\title{
HIGHER DIMENSIONAL COMPACTNESS OF HARDY OPERATORS INVOLVING OINAROV-TYPE KERNELS
}

\author{
PANKAJ Jain, PAWAN K. JAIn AND Babita GuPta
}

Abstract. The compactness of the higher dimensional generalized Hardy operator $(\mathcal{K} f)(x)=$ $\int_{S_{x}} k(x, y) f(y) d y$ and its conjugate operator $\mathcal{K}^{*}$ has been characterized for the case $1<p$, $q<\infty$. This is done by reducing the problem to the corresponding one dimensional situation.

Mathematics subject classification (2000): 46E35, 26D10.

Key words and phrases: Hardy operator, Oinarov kernel, boundedness, compactness.

\section{REFERENCES}

[1] T. ANDO, On the compactness of integral operators, Proc. Ned. Akad. Van Wet., 24, (1962), 235-239.

[2] S. Bloom, R. Kerman, Weighted norm inequalities for operators of Hardy type, Proc. Amer. Math. Soc., 113, (1991), 135-141.

[3] B. GuPTA, Mapping Properties of Certain Integral Averaging Operators, Doctoral Thesis, 2004.

[4] P. JaIn, B. GUPTA, Compactness of Hardy-Steklov operator, J. Math. Anal. Appl., 288, (2003), 680-691.

[5] P. JAIN, P. K. JAIN AND B. GUPTA, Compactness of Hardy-type operators over star-shaped regions in $\mathbb{R}^{N}$, Canad. Math. Bull., 47, (4) (2004), 540-552.

[6] A. KufNer, L. E. Persson, Weighted Inequalities of Hardy Type, World Scientific, 2003.

[7] E. Lomakina, V. D. Stepanov, On the Hardy-type integral operators in Banach function spaces, Publ. Math., 42, (1998), 165-194.

[8] V. G. MAZ'JA, Sobolev Spaces, Springer Verlag, Springer Series in Soviet Mathematics, 1985.

[9] R. OINAROV, Weighted inequalities for a class of integral operators (Russian), Dokl. Akad. Nauk. SSSR, 319, (1991), 1076-1078; translation in Soviet Math. Dokl., 44, (1992), 291-293.

[10] R. OINAROV, Two-sided estimates for the norm of some classes of integral operators (Russian), Trudy Mat. Inst. Steklov, 204, (1993), 240-250; translation in Proc. Steklov Inst. Math., 204, (1994), 205-214.

[11] G. Sinnamon, A weighted gradient inequality, Proc. Royal Soc. Edinburgh Sect. A, 111, (1989), 329-335.

[12] G. Sinnamon, One dimensional Hardy-inequalities in many dimensions, Proc. Royal Soc. Edinburgh Sect. A, 128A, (1998), 833-848.

[13] A. Wedestig, Weighted Inequalities of Hardy-Type and their Limiting Inequalities, Doctoral Thesis, 2003. 